Article

\title{
From Deinstitutionalization to Community-Based Urban Development: Investigating Accessibility of Urban Systems in Calabria through Network Analytics
}

\author{
Carmelina Bevilacqua (D), Pasquale Pizzimenti *(D), Nourhan Hamdy and Federica Mangiulli
}

check for

updates

Citation: Bevilacqua, C.; Pizzimenti,

P.; Hamdy, N.; Mangiulli, F. From

Deinstitutionalization to

Community-Based Urban

Development: Investigating

Accessibility of Urban Systems in

Calabria through Network Analytics.

Sustainability 2022, 14, 1348. https://

doi.org/10.3390/su14031348

Academic Editor: Brian Deal

Received: 21 December 2021

Accepted: 21 January 2022

Published: 25 January 2022

Publisher's Note: MDPI stays neutral with regard to jurisdictional claims in published maps and institutional affiliations.

Copyright: (c) 2022 by the authors Licensee MDPI, Basel, Switzerland. This article is an open access article distributed under the terms and conditions of the Creative Commons Attribution (CC BY) license (https:// creativecommons.org/licenses/by/ $4.0 /)$.
CLUDsLab, PAU Department, Università degli Studi Mediterranea of Reggio Calabria, 89124 Reggio Calabria, Italy; cbevilac@unirc.it (C.B.); nourhan.hamdy@unirc.it (N.H.); federica.mangiulli@unirc.it (F.M.)

* Correspondence: pasquale.pizzimenti@unirc.it

\begin{abstract}
Community-based urban development is an inclusive approach for local service provision and management centered on the proactive partnerships between urban communities and local governments. Rooted in the deinstitutionalization of public services, the European Union and national policy effort is pushing towards the organization of community-based alternatives in response to the evolving needs of local communities. As the pandemic has shown, service accessibility has proven to be a key concern element that needs to be addressed to increase communities' and cities' resilience. In this direction, the paper aims to propose data-driven alternative approaches to assess urban systems' accessibility and connectivity as an element of leveraging the resilience-oriented planning process and facilitating community-based development. The methodological approach focuses on the case of the Calabria region, where community-based alternatives for the provision of public services found difficulties to be operationalized through an integrated planning approach. The case study is explored by experimenting on the spatial connections of two purposefully selected clusters to assess the accessibility and connectivity of urban systems within the region through network analysis visualization tools: health and social-related services and transportation and logistics. The analytical approach outlines the accessibility level of urban systems in the region examined, proving its relevance in detecting social, economic, and environmental dynamics. This approach shows how using non-traditional data-driven perspectives can detect development dynamics-which affect local community's needs-and their limitations in the organization of community-based development alternatives.
\end{abstract}

Keywords: data-driven approach; community-based urban development; urban accessibility

\section{Introduction}

The current severe challenges, such as climate change and the pandemic outbreak, have pushed cities to rethink urban development strategies by addressing their persistent social, economic, and environmental vulnerabilities in the transition towards resilience and sustainability [1]. Some of the shocks or stresses affecting our cities are difficult to predict, and others result from the persistent vulnerabilities shaped by policy and regulatory choices [2]. The OECD [2] has recently reported the lessons learned from the consequences of the pandemic and the response of cities across the world in the short- and long-term perspective, which can inform the revision of future urban policy: digital divide, urban mobility, urban density, urban planning and design, and collaborative governance. If the aim of the current policy approach for the recovery from the pandemic is oriented toward the green, digital and resilient transition of cities and regions [3], the response to the evolving local communities' needs with inclusive urban planning approaches and collaborative and multilevel governance will prove to be a central element for the recovery. In this direction, as also revealed in the context of COVID-19, the importance of engaging urban stakeholders and citizens towards community-based urban development (CBUD) 
is gaining relevance [4]. The EU and national policy efforts towards community-based development are rooted in the policy shift towards deinstitutionalizing public services [5]. However, some regions are still finding difficulties in operationalizing comprehensive strategies to support communities at the local level and sustain cities' capacity for sustainable urban transformation in a broader sense [6]. The pandemic and its aftermath are prompting cities to rethink how they deliver services, how they plan their space, and how they can resume economic growth [2]. In addition, it has revealed how community-based services-especially in the case of health care services and facilities-have affected the quality of life of local communities and vulnerable categories [2]. Schalock et al. [7] identified eight core areas of quality of life: emotional well-being, physical well-being, material well-being, social inclusion, social relations, personal development, self-determination, and civil rights [7], which also influence the overall local community life [8,9]. In the future city, which "is ecologically and economically resilient," healthy and livable neighborhoods are available and accessible to all people [10] (p. 5). Improving the quality of life for local communities implies specific efforts to facilitate a more inclusive urban development. Therefore, equity, inclusiveness, urban accessibility, and sustainability can be considered the pillars for the paradigmatic shift towards resilience. In this direction, deinstitutionalizing public services offers the basis to rethink cities' urban development, facilitating a more inclusive transition towards resilience and sustainability. In the shift from institutionalization to community-based services, accessibility increases people's quality of life [11]. From this perspective, the pandemic has strongly impacted mobility and accessibility, and cities are rethinking the location of essential urban functions to ensure easier access to urban services and amenities while securing safety and health for their residents [12].

We argue that local authorities should better address the evolving needs of local communities by promoting a more inclusive urban development from a community-based perspective. Better comprehension and knowledge of the change over time of the local communities' needs can provide the ground to foster integrated planning approaches for public services and management inspired from a community-based development approach. Furthermore, the introduction of big data analysis techniques, urban models, and network theory can expand the knowledge about cities and urban phenomena. In this direction, alternative data-driven approaches can offer interesting insights to support the design and the implementation of integrated solutions to connect local governments, community-based organizations, and citizens.

Given these premises, our central research question is the following: Could innovative and alternative data-driven approaches help detect changes in urban systems' dynamics to foster integrated planning solutions for the provision of an adequate community-based response to local communities' needs?

In this direction, the paper proposes a data-driven alternative approach to assess urban systems' accessibility as a different interpretative modality to develop integrated planning solutions following the community-based development rationale. In this direction, the Calabria region is selected as a case study given the difficulty of operationalizing community-based alternatives for the provision of public services through an integrated planning approach.

The paper is organized as follows. The next section focuses on the paradigmatic shift from institutionalization to the deinstitutionalization of services rooted in communitybased urban development. This section provides the ground for the inquiry presented in the paper, specifically the relevance of accessibility in the definition of resilient local communities and the relevance of the spatial perspective in planning and delivering public services at the community level, as the Italian experience suggests. Next, the methodological section focuses on the case of the Calabria region, where community-based development alternatives rooted in the integrated planning approach for public services provision find difficulties to be operationalized. The case is explored by experimenting with the spatial connections of clusters to assess the accessibility and connectivity of urban systems within the region by exploiting network analysis visualization tools. The analytical 
approach outlines the accessibility level of urban systems in the region examined, proving its relevance in detecting social, economic, and environmental dynamics if integrated with complementary data sources and explored over time. This aspect proves how looking at the connectivity and accessibility of urban systems using non-traditional data-driven perspectives can detect development dynamics affecting local communities' needs and limitations. The outcomes of this process reveal interesting insights on the urban systems and their context conditions, providing additional information on local communities' needs and their changes over time. If purposefully integrated with complementary data sourcesand explored over time-this process can provide useful information to target integrated and coordinated policies through community-based development actions in specific areas for the post-pandemic recovery of cities.

\section{Background}

\subsection{From Deinstitutionalization to Community-Based Urban Development}

The provision of social services primarily affects individuals and households [13]. Their quality is critical to the life of citizens [14]. With the aim of delivering more tailored and effective public services, there has been a policy effort at the European and national levels to shift from institutionalized services to family-based and community-based alternatives following the deinstitutionalization approach [5]. Several international conventions provide the context for such a policy shift, including the 1948 Universal Declaration of Human Rights and, more recently, the 2006 UN Convention on the Rights of Persons with Disabilities and the more recent UN Sustainable Development Goals (SDGs) [15]. UN SDGs provide the context for national, regional, and local governments to advance a new sustainable development paradigm. It provides a vision to engage local stakeholders, including the private sector and civil society, in co-creating and building the "resilient community". Despite the explicit goal of sustainable cities and communities (SDG 11) [15], others can be included in promoting inclusiveness and reducing inequalities in cities from a community-based development perspective (Table 1).

Table 1. UN SDGs [15] addressed by the topic under investigation.

\begin{tabular}{|c|c|}
\hline SD Goal/s & Aim \\
\hline 3-Good health and well-being & $\begin{array}{l}\text { Ensure healthy lives and promote well-being for all } \\
\text { at all ages }\end{array}$ \\
\hline 4-Quality education & $\begin{array}{l}\text { Ensure inclusive and equitable quality education } \\
\text { and promote lifelong learning opportunities for all }\end{array}$ \\
\hline 10-Reduced inequalities & Reduce inequality within and among countries \\
\hline 11-Sustainable cities and communities & $\begin{array}{c}\text { Make cities and human settlements inclusive, safe, } \\
\text { resilient and sustainable }\end{array}$ \\
\hline 16-Peace, justice and strong institutions & $\begin{array}{c}\text { Promote peaceful and inclusive societies for } \\
\text { sustainable development, provide access to justice } \\
\text { for all and build effective, accountable and inclusive } \\
\text { institutions at all levels }\end{array}$ \\
\hline
\end{tabular}

The deinstitutionalization concept is traditionally associated with mental health and intellectual disability [16]. In the framework of deinstitutionalization, research has consistently demonstrated how this approach produces a better outcome for people than institutionalized care [8,9,16-22]. Deinstitutionalization was introduced in the 1950s to shift from institutional (as in a psychiatric hospital) to community care. Subsequently, the initiative was extended to other public services. In some countries, there was a shift from the initial focus on closing institutions and replacing them with smaller staffed houses in the community to more individualized options such as supported living, direct payment methods, and personal or individualized budgets [20]. Some researchers have indicated that these individualized approaches bring additional benefits to people, especially in terms of choice and control [22,23]. The effects of the pandemic across territories have highlighted the importance of community-based alternatives in delivering services to 
vulnerable categories [2]. This is especially true for healthcare services and facilities [2]. In the context of this work, deinstitutionalization is related to the shift of general public services from an institutionalized to a community-based perspective. This communitybased vision characterizes the socially inclusive urban development for the contemporary city as it addresses socio-economic disparities [24]. Within this process, rooted in the deinstitutionalization approach, community-based organizations (CBOs) are important actors. $\mathrm{CBOs}$ provide different and valuable programs and services; they network and develop partnerships between organizations in urban contexts where it is necessary "to build coalitions, exchange/share resources, partner, and avoid service duplication," and provide services and support to the most vulnerable social categories [25] (p. 1). Despite their relevant role in improving local socio-economic conditions, their adaptation to the mutated scenario for delivering these benefits in the future is coming to the fore [26]. By considering the deinstitutionalization approach and the primary role of $\mathrm{CBOs}$ in providing health care services to vulnerable people, accessibility proves to be a central issue to address [25]. As the pandemic has shown, accessibility to primary care services offered by $\mathrm{CBO}$ - - or even to green spaces or public spaces in general and infrastructures-is one of the key factors for intervention in resilience-building strategies [11]. Indeed, accessibility to infrastructures and urban services can facilitate or limit community resilience [27]. Specifically, assessing urban connectivity and accessibility to address social vulnerabilities is an essential element of the urban resilience strategies [11], and the principles of urban transition towards sustainability are being experimented with in the Driving Urban Transition approach [28]. Improving accessibility in the resilience-oriented perspective also means ensuring "adequate urban mobility and transportation interventions" [29] (p. 7) because sustainable and accessible urban mobility systems have the potential to address social cohesion, housing, economic development, and public health issues [29]. The focus on urban connectivity and mobility allows the urban policy actions to be widened towards social inclusion through the provision of public spaces, increasing the sense of community and the engagement of community-based stakeholders [30]. Moreover, transportation and transit accessibility are key elements in assessing urban resilience [9]. Regional, metropolitan, and intra-metropolitan public services and transportation networks allow cities to experiment with Driving Urban Transition approaches, which require supportive zoning regulations to facilitate the creation of the 15 min city [28].

\subsection{The Italian Policy Approach: Providing the Ground for Community-Based Urban Development}

The Italian policy approach for the organization and delivery of public services for vulnerable categories is rooted in the national law no. 328/2000 for the design and implementation of integrated social services and actions (Legge quadro per la realizzazione del sistema integrato di interventi e servizi sociali). The reform was introduced to overcome the fragmentation of the Italian social service system by addressing three key aspects: "the weak coordination among various institutional level, the huge difference existing between territories, and the vagueness and disparity of rights" [31] (p. 213). Following the reform, the public intervention in the design and management of social services was articulated in the involvement of different political-administrative levels: regions, provinces, and municipalities [31]. The regional administration has the task of planning, coordinating social and health interventions and verifying their implementation, regulating the integration of the interventions themselves, and promoting collaboration with local authorities. Municipalities have the task of designing and implementing Local Welfare Plans (Piani di Zona sociale), which can be designed and implemented by aggregating other municipalities [31]. The Local Welfare Plan is a tool to organize and provide social services and interventions for local communities at the local level with specific objectives based on the analysis of the territorial context, the analysis of the qualitative and quantitative evolution of local communities' needs, the development of flexible management provision of services, the integration of public and private resources to avoid duplication and fragmentation, the definition of new opportunities and attraction of new resources, the definition of the 
services to deliver according to the responsibilities of the actors involved and the available resources also involving citizens [32]. The regional administration defines the areas where such plans find their operationalization following the district rationale. In the case of big cities, such districts target one or more neighborhoods. In the case of small and medium cities, these areas target more municipalities. These areas are determined based on criteria that can facilitate the deinstitutionalization of services following the community-based development perspective and usually group several municipalities. Such criteria are related to the geomorphological configuration, local community needs, the possibility to share resources and common territorial services, the transportation system's efficiency, accessibility of services, and previous co-design [33].

Although this policy was introduced almost twenty years ago, some regions still encounter difficulties operationalizing it. For example, this is the case of Calabria, where such integration is not yet fully developed. The Calabria regional administration has designed the regional welfare plan according to the national law 328/2000. It has recently deployed preliminary measures to integrate welfare and urban planning tools [34] to better address public services.

As the Local Welfare Plan shows, the effective planning, organization, and administrative management of public services are essential for local administrations to respond to the local communities' needs [35]. Such effectiveness determines the quality of services, quality of life, and social, economic, and territorial cohesion. Then, two elements emerge. First, the organization of services for post-pandemic cities should follow the deinstitutionalization approach by promoting the community-based approach to facilitate accessibility. In this vision, the accessibility of urban services for local communities is a crucial element to enable community resilience. Second, within the current institutional and planning framework, the organization and planning of services require a territorial/spatial perspective shift from the municipal or inter-municipal level to the neighborhood level. Data-driven approaches can help in this direction, providing interesting support in detecting socioeconomic development dynamics and capturing the evolving local communities' needs to address.

\section{Methodology}

The methodology explores alternative data-driven approaches to support resilience planning processes for creating sustainable, equitable, and economically strong communities [9]. In the light of urban resilience and transition strategies, accessibility has proven to be a central element for local communities. Therefore, the methodological approach focuses on the accessibility of urban systems by attempting the detection of the evolution of local communities' needs as a way to differently interpret the provision of public services, which should be planned according to an integrated approach. Accessibility has proven to be a critical element for vulnerable categories during the pandemic [2]. Addressing this aspect through sustainable mobility and transportation systems is important in increasing local communities' resilience [11]. Moreover, in the policy framework of cities' transition, sustainable mobility is one of the pillars for creating a future carbon-neutral city [28]. Then, detecting and understanding the current level of accessibility of urban systems provides useful insights in rethinking cities and urban policy in the post-COVID-19 world.

The analytical approach adopted in this paper is articulated in two main steps. The first step is rooted in the spatialization of economic clusters intended as the geographic concentration of economic activities [36]. For this paper, clusters are relevant as they can be used to explain the complex interrelationships between the environment and human activities following the interpretation of cities as socio-ecological systems [37]. These interrelationships generate a growing demand for resources necessary for human activities, including services, food, health, and safety, revealing complementary information on local community needs.

The second step visualizes the connections between clusters' sectors and the context using network analysis tools. Network analysis is a type of analysis consisting of nodes 
and ties [38]. Although network analysis may be a marginal research tool, in the recent past, several studies have included it in the investigation of urban agglomerations and "global cities" [39], innovation [40], and evolutionary economic geography [41,42]. Thus, the application of network analysis is becoming increasingly relevant, reflecting a broader trend towards the investigation of relational perspectives [43]. Furthermore, the application of network analysis using the geospatial localization of clusters allows the interactions between clusters' sectors and the context to be visualized graphically, highlighting the weak links in a system and the emergence of new connections over time.

The Calabria region is selected as a case study to implement this analytical approach, given the difficulty of operationalizing the delivery of community-based solutions. Two clusters have been purposefully selected to assess the accessibility and connectivity of urban systems in the region: Transportation and Logistics and Health and Social Assistance. Labor market area (LMAs) data have been used to localize industries belonging to the cluster, as they provide data on industries' localization and labor force. Network analysis tools are then used to visualize LMA connections in Calabria for the cluster under investigation.

The relevance of this process is twofold. First, it provides an alternative data-driven approach to assess the connectivity and accessibility of urban systems from a spatial perspective. Moreover, thanks to network analysis tools, this process allows visualizing the strong, weak, or emergent connections of economic sectors and activities within the region, unveiling the evolving needs of local communities. Second, by identifying the connectivity and accessibility level of the urban systems, this data-driven approach detects and outlines those areas within the region where accessibility and connectivity can be improved, providing complementary information for the definition of targeted and tailored community-based urban development actions towards resilience.

\subsection{Measuring Connectivity and Accessibility of Urban Systems in Calabria}

The case study unit of analysis is the Calabria region, categorized as a Less Developed Region for the EU programming period 2021-2027. It is a NUTS III Level region with two million inhabitants and a surface of $15.222 \mathrm{~km}^{2}$, representing about $5 \%$ of the Italian territory. The Calabria region presents weak socio-economic performance indicators among the southern Italian "less developed regions". As an example, it shows very high poverty at the individual (34.6\%) and family (30.6\%) incidence levels compared to the national level $(15.0 \%$ and $11.8 \%$ respectively) [44], and a gross domestic product (GDP) of 33,619.41 MEUR [45] (see Tables 2 and 3).

Table 2. Individual and family relative poverty rate in Southern Italian "less developed regions" (Source Istat, 2021) [44].

\begin{tabular}{cccccc}
\hline Indicator & Calabria & Sicily & Campania & Puglia & Italy \\
\hline Individual relative poverty rate $(\%)$ & 34.6 & 26.0 & 29.5 & 22.8 & 15.0 \\
\hline Family relative poverty rate $(\%)$ & 30.6 & 22.5 & 24.9 & 20.0 & 11.8 \\
\hline
\end{tabular}

Table 3. Gross domestic product (source, Eurostat 2021) in Southern Italian Regions-less developed regions (MEUR) [45].

\begin{tabular}{cccccc}
\hline Indicator & Calabria & Sicily & Campania & Puglia & Italy \\
\hline $\begin{array}{c}\text { Gross Domestic Product } \\
\text { (Millions of Euro) }\end{array}$ & $33,619.41$ & $89,365.04$ & $109,630.67$ & $77,475.32$ & $1,789,747$ \\
\hline
\end{tabular}

Concerning the delivery of social and health-related services, the region designed the Regional Welfare Plan according to the reform no. 328/2000. The strategic vision at the regional level is operationalized through the Local Welfare Plan in the districts designed by local authorities. 
The socio-health local district has the mission to respond to the local communities' needs providing the primary care and health services required by law. Although the region is relatively small, there is an increasing concern with the definition of regional strategies that can better address the delivery of primary care and health services at the local level. The current institutional and organizational structure, operationalized in the district, covers a wide geographical area due to the per capita ratio in the planning and delivery of services. As Figure 1 shows, the designed districts in the region include several municipalities, making it difficult for the effective organization and planning of services provided to facilitate proximity of primary care and health facilities to local communities. In this direction, looking at the articulation of urban systems' accessibility can provide interesting insights to better reorganize public services within the districts favoring proximity to citizens according to the community-based development approach.

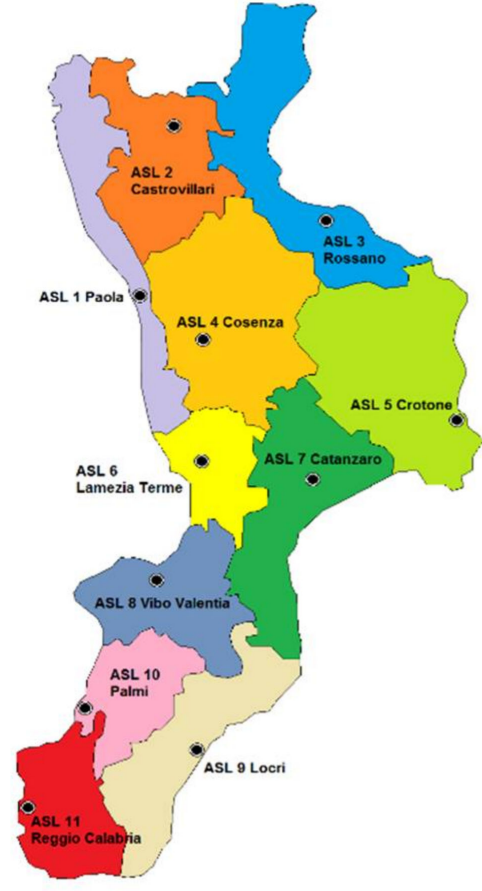

(a)

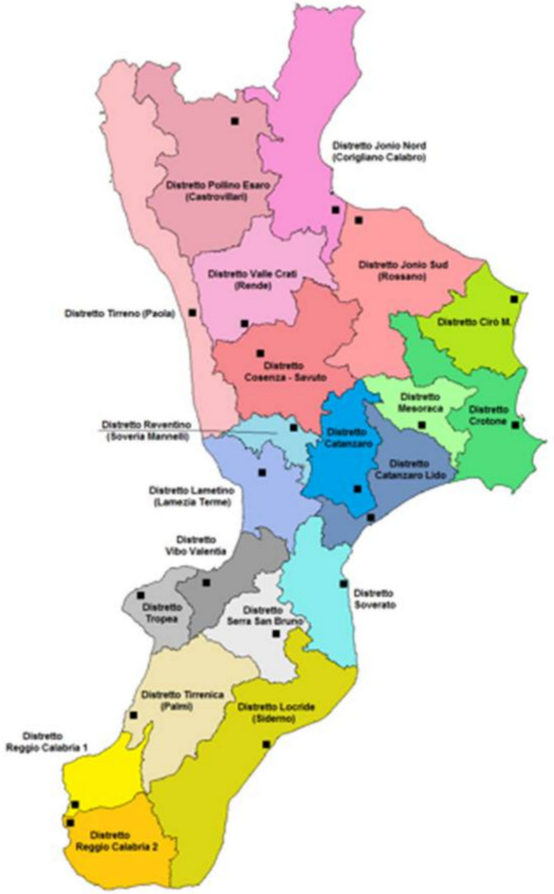

(b)

Figure 1. Calabria region territorial organization of the welfare system: (a) territorial areas-ASL; (b) districts for the organization and planning of services delivery.

\subsection{Data Collection}

In the literature, some studies have defined the boundaries of clusters according to state boundaries [17,36-39]. Others have chosen a more precise unit of analysis, the metropolitan statistical area, to more clearly connect enterprises to their region's economic activity and consider situations where there may be multiple clusters in a single region [36]. In this study, we used LMAs as the spatial unit for the investigation (Figure 1). LMAs are "subregional geographical areas where the bulk of the labor force lives and works, and where establishments can find the main part of the labor force necessary to occupy the offered jobs" [46]. LMA data have been recognized to have an explicit validity that is relevant "to release information and statistics on employment and socio-economic structures, as well as for assessing the effectiveness of regional policy decisions and local government reorganization" [47]. This alternative approach to measure territorial phenomena is gaining importance for analytical purposes, raising the interest of policymakers [48]. The case study under investigation presents forty-five $(\mathrm{N}=45)$ LMAs (See Figure 1).

Our analysis highlights geographically concentrated industries, borrowing Porter's cluster definition (2003) [36]. By mapping industries' concentration, we can statistically 
trace regional agglomerations of enterprises and/or employment. Furthermore, using network analysis allows the linkages in industry networks to be identified and the strength of connections between industry sectors and urban systems to be examined. Given data availability, data have been retrieved for 2012-2018 with a specific focus on 2018 to obtain the most recent picture of urban systems' accessibility. The dataset provides the number of active local enterprises (establishments) in Calabria in NACE 3- and 4-digit sectors (see Table 4).

Table 4. Data collection format.

\begin{tabular}{ccc}
\hline \multicolumn{3}{c}{ Transportation and Logistics Cluster/Health and Social Assistance Sectors } \\
\hline & Year & 2012-2018 \\
\hline Data & Number of active establishments local units \\
\hline Ateco 2007 & Data & Ateco Code 2007 by cluster \\
\hline LMA code & Unit & \\
\hline & Italy & \\
\hline & Sud \\
\hline
\end{tabular}

\subsection{Visualizing Connectivity and Accessibility of Urban Systems through Network Analysis Tools}

The health and social assistance economic sectors have been considered, as they provide complementary data related to the delivery of public services from the health and social assistance perspective. The transportation and logistics cluster is purposefully used to better examine the connectivity of urban systems in the region given its focus on "the management of the flow of goods or people and the actual process of transport between a starting point and a specific destination, which may be land-, air- or space-based" [49] (p. 56). The cluster is articulated in ten sectors (Table 5), covering all the land, maritime, and air transportation activities of goods and people.

Table 5. Transportation and logistics, and health and social assistance service cluster sectors [50].

\begin{tabular}{ccc}
\hline Cluster & Sectors & LMAs Ateco Code \\
\hline & Repair and maintenance of aircraft and & 3316 \\
spacecraft & 4939 \\
Transportation and & Transport of goods by road & 4941 \\
Logistics & Air transport of passengers & 5110 \\
& Cargo transportation by air & 5121 \\
& Service activities ancillary to land & 5221 \\
& transportation & 5223 \\
& Service activities ancillary to air transport & 5224 \\
Health and Social & Handling of goods & 5229 \\
Assistance & Other transport support activities & $86(861,862,869)$ \\
& Residential social assistance services & $87(871,872,873)$
\end{tabular}

Data collected for LMAs have been computed using the network analysis software Gephi. From a quantitative perspective, a network consists of a set of actors or vertices and a set of edges [51] expressed formally by the following:

$$
G=(\mathcal{N}, \mathcal{E})
$$


where $G$ is our network, $N$ is the set of nodes, and $E$ is the set of edges which are unordered pairs of elements of $N$. The structure of complex networks can be represented as a graph [52]. Costa [52] specifies that the network can be represented by its adjacency matrix A (Figure 2). In our analysis, 'ties' between industries and LMAs resulted from firms' birth in those areas, which means different LMAs are connected through one or more of the mutual industries between them. More specifically, LMA nodes are connected to their geographic position by applying the Geo layout in the software data processing. The size of the LMAs' nodes $\mathrm{N}$ (blue nodes) reflects the total number of units in all sectors found in those LMAs (Figure 3a,b). Edges $E$ indicate linkages between territories (geolocalized LMAs) and industries (cluster's sector) (Figure 2). The use of network analytics identifies the linkages between LMAs and sectors (Figure 4). The relationship between nodes is considered undirected, as there is no specific input from one node to the other (see Figure 4).

\section{Calabria Region Local Labor Market Areas LMAs}

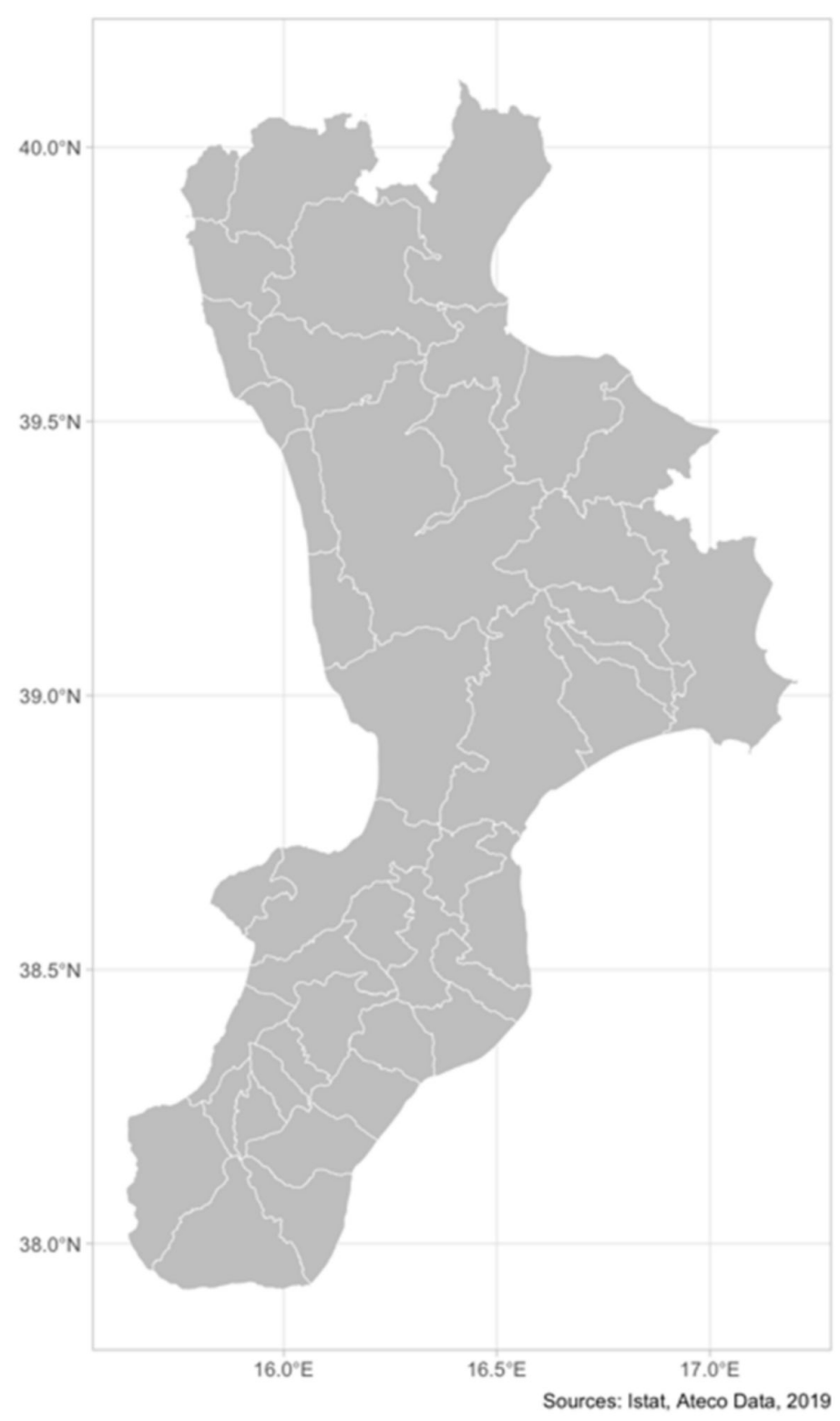

Figure 2. Calabria region labor market areas (LMAs). 


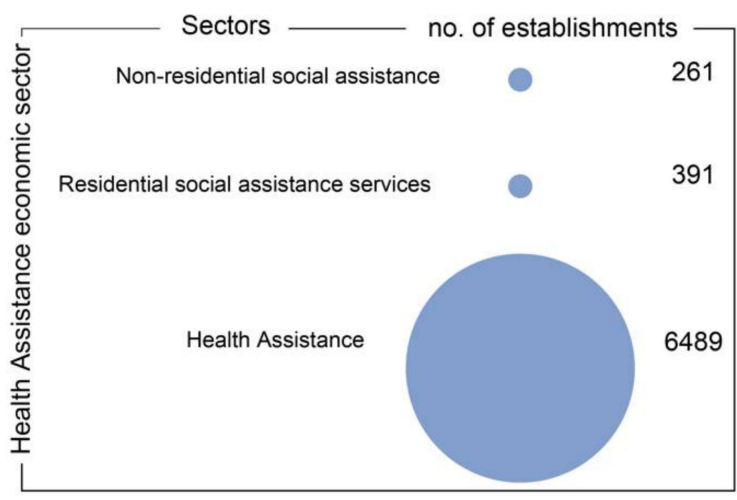

(a)

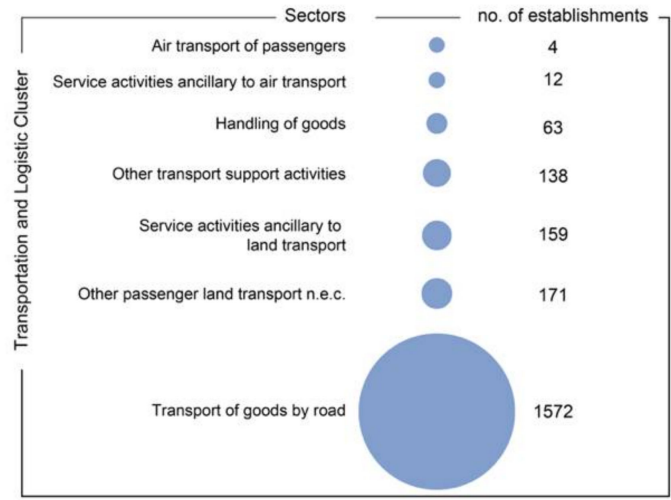

(b)

Figure 3. Nodes of the network: (a) Health Assistance economic sectors; (b) Transportation and Logistic cluster sector.

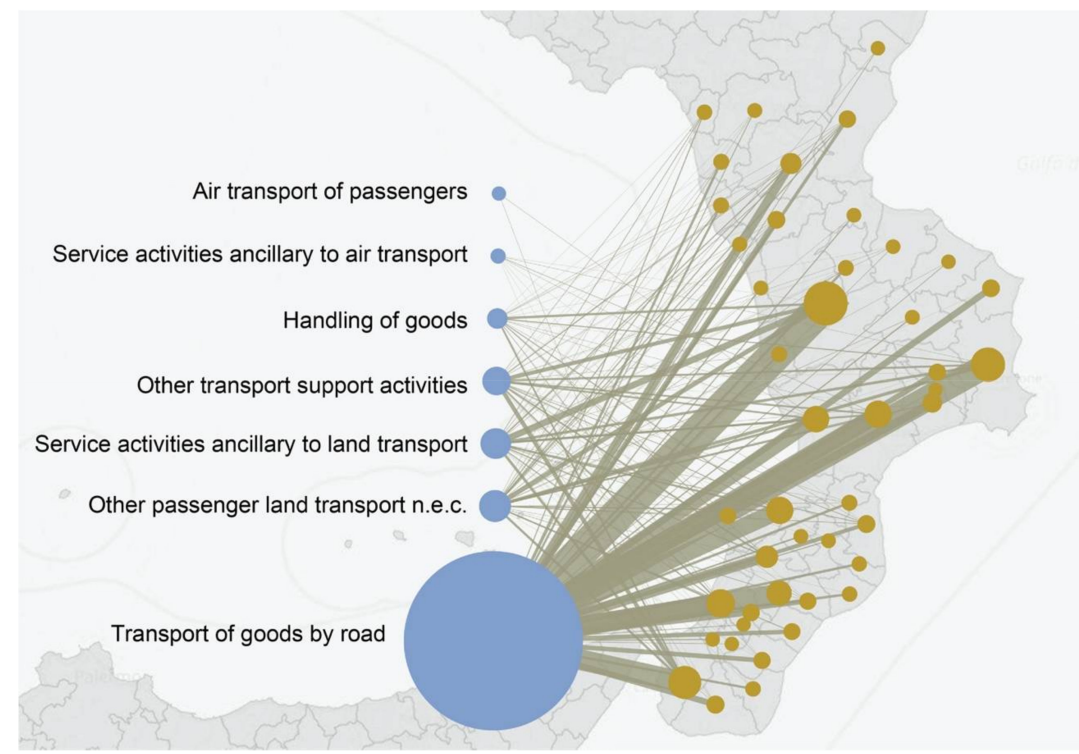

(a)

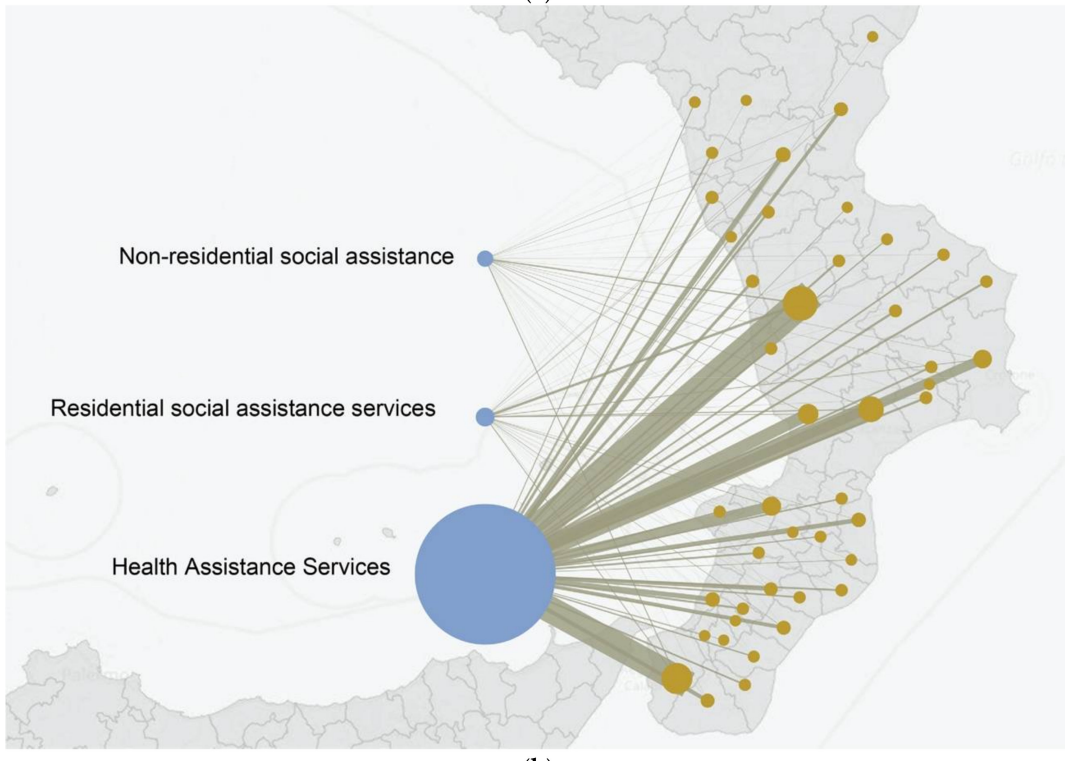

Figure 4. Data-driven network visualization: (a) Health Assistance economic sectors; (b) Transportation and Logistic cluster sector per LMA in Calabria. 


\section{Results and Discussion}

The methodology adopted in this work attempted to explore alternative data-driven approaches to support resilience planning processes for creating sustainable, equitable and economically strong communities. The pandemic outbreak has proven how accessibility to urban services-especially to the health-related facilities-was one of the main concerns to address, as accessibility affected local communities and especially vulnerable groups of people. As a result, and as suggested by recent research on urban transition [28], increasing the level of accessibility of services, including through sustainable mobility and transportation, can facilitate the transition of cities towards resilience and sustainability. Therefore, detecting and understanding the current level of accessibility of urban systems starting from health-care-related services can provide useful insights for the better provision of public services if included in an integrated planning approach.

Given the increasing relevance of alternative data-driven approaches to increase the knowledge of cities and urban phenomena, we explored the potential of network analysis visualization tools as an alternative option to detect the accessibility of urban systems in the Calabria region, where integrated planning solutions for the provision of health-related and public services are difficult to be operationalized. We started our case analysis from the geographic concentration of businesses (clusters) in the region as their concentration can provide insights into the regional development dynamics. The cluster "transportation" and the cluster "health-related services" have been selected as "proxy" to detect the level of accessibility and connectivity of the urban system and the change in local communities' needs. Using the network visualization of these clusters makes it possible to draw some interesting insights.

First, the present study outlines an alternative perspective on the accessibility and connectivity level of urban systems within a region starting from the analysis of clustersintended as the geographic concentration of economic activities. Regarding the number of establishments per LMAs in the cluster, the LMA of Cosenza shows the highest value (285), followed by Crotone (193), Reggio Di Calabria (180), Gioia Tauro (138), Catanzaro (128), Vibo Valentia (127), Lamezia Terme, and Polistena, respectively (119 and 107). However, the LMA of Cosenza is not connected to all sectors, such as the air transport of passengers sector. The only 2 LMAs connected to all sectors are Lamezia Terme and Reggio Di Calabria, where two airports are located. Despite the presence of three airports in the region-Lamezia Terme, Reggio Calabria, and Crotone-the LMA codes related to aircraft maintenance and repair (3316), air transport of passengers (5110), and cargo transportation by air (5121) show a low number of establishments active in the region. Within the overall Transportation and Logistics cluster, the transport of goods by road sector is the region's most active (1562 establishments). Additionally, it presents the highest number of shares between all the LMAs. The LMA of Cosenza has the highest number of local units of active enterprises (187 units) in this sector, followed by Crotone (141 units), Reggio Di Calabria, and Gioia Tauro (116 and 114 units, respectively). In the LMA of Cosenza, the transportation of goods by road accounts for 65 percent of the entire cluster. On the contrary, fifteen (15) LMAs show less than ten establishments for the transportation of goods by road sector in all Calabria. From Figure $4 b$, it is possible to notice that despite the LMA of Cosenza having the highest number of connections (285 establishments), the connections of the LMAs located in the province of Reggio Calabria show better urban systems connections. In addition, this province shows the presence of a national airport (Reggio Calabria) and an international trade port (Gioia Tauro). Data on these clusters show a generally poor level of urban systems' accessibility in the region, considering all the sectors belonging to the clusters examined. Train, air, and maritime transportation of people and goods present a lower number of establishments than transportation goods by road. Looking at the health and social assistance economic sector, it shares the highest number of connections (6849), followed by the social non-residential assistance (391) and the residential social assistance sectors (261). For the entire Health and Social assistance service sector, the LMA of Cosenza has the highest number of establishments (1193), followed by Reggio 
Calabria (1000), Catanzaro (733), Lamezia Terme (473), Vibo Valentia (403), and Crotone (382). In general, the LMAs with the higher accessibility value also show a higher share of connections in the Health and Social services economic sector. In the case of the Reggio Calabria province, where we have good accessibility for almost all the LMAs, we have a concentration of establishments per the entire Health and Social Services sector in the Reggio Calabria LMA but an overall good distribution of services in the entire province. In the provinces of Cosenza and Catanzaro, it is possible to notice a high concentration in the Cosenza and Catanzaro LMAs and a weaker connection of the other LMAs in the province compared to Reggio Calabria. The network visualization process highlights how in the LMAs where the level of accessibility by road is high, the occurrence of health and social assistance services establishments is high.

Second, the analytical approach centered on clusters reveals the interactions between human activities and territories by interpreting the city as a socio-ecological system [37]. In this direction, dynamic networks help understand sectors' evolution as they contribute to the investigation of industries' development, the spatial evolution of networks, and when relationships were formed, maintained, and broken $[53,54]$. Potentially, by generating the same network in 2012-2018, it is possible to detect the industries' agglomeration from an evolutionary perspective. Furthermore, the tracking of change over time using network analysis techniques and measures (e.g., centrality) makes it possible to shed light on sectoral changes contextualized within regional industrial shifts and track and detect the evolving local communities' needs.

Third, the visualization of clusters' structure and evolution through dynamic networks has the potential to graphically visualize which industries and territories can in-novate together by pinpointing weak links in a system and the emergence of new sectors over time. At the same time, as the case study analysis shows, identifying the strong or weak ties can contribute to determining the level of urban accessibility and connectivity of urban systems. Finally, detecting clusters' dynamics can reveal the evolution of local communities' needs, as clusters explain the complex interactions between socio-ecological and socio-technical systems.

\section{Conclusions}

Urban resilience and urban transition are central elements to drive the strategic development of cities for post-pandemic recovery. In both strategies, the social dimension is important, and community-based urban development can represent a way to overcome the limits of the pre-pandemic urban development paradigm. The pandemic outbreak has heavily affected cities and local communities [55]. Accessibility to public services, especially to health-related facilities, constituted one of the main concerns for cities. This point highlights the need to rethink the organization and the delivery of public services for cities following a community-based development perspective. In this direction, the European and national policy efforts are pushing towards a paradigmatic policy shift from institutionalization to community-based alternatives. The Italian experience shows interesting insights. Local Welfare Plans can provide useful information and actions to address local communities' needs. Their integration with the Italian urban planning tools following a neighborhood-based perspective can represent an opportunity to implement community-based urban development actions to facilitate the post-pandemic city's just, green, and digital transition.

Local Welfare Plans provide the demand for urban public services, and urban planning tools organize the offering and delivery of these services in urban areas according to community needs. However, as the case study shows, 21 years after the approval of Law no.328/2000, such integrated and coordinated policy actions to organize and support community-based services rooted in the deinstitutionalization approach in Calabria are not yet operationalized, as they are limited only to the Welfare dimension (their integration has been proposed only recently). The lack of community-based alternatives in the provision of public services does not ensure that those left behind (i.e., migrants, low-wage workers) are 
targeted with tailored employment and activation programs that are adaptable, relevant, flexible, and responsive to the emerging needs of local communities. Community-based development is a suitable framework that allows such integration. It facilitates urban partnerships between local governments, community-based organizations, universities, civil society, and citizens, providing the ground to increase communities' and cities' resilience. Implementing a coordinated and integrated policy perspective can benefit from alternative, multi-scalar and multi-dimensional data-driven approaches. Additionally, given the increasing relevance of big data, urban models and network theory can contribute to deepening the knowledge on cities and urban phenomena [56]. Besides the traditional tools and variables used to measure social inclusion, urban connectivity and accessibility to services have proven to be interesting elements to measure the ability of urban systems towards inclusive development. Improving urban accessibility for the most vulnerable categories (i.e., elderly, families with children, disabled) can facilitate social inclusion and cohesion and sustainable transportation and mobility systems. The proposed analytical approach can help integrate the regional and local synergy to activate the social and planning nexus. Using network analysis visualization, we offered an alternative analytical perspective for assessing the accessibility and connectivity of urban systems, which can contribute to expanding - supported by traditional data and approaches- the knowledge on cities and urban phenomena.

However, this work presents some limitations. Besides secondary data being partially allowed to reach our aims, the fact of not having primary data does not allow us to draw deep findings regarding the innovative behavior of the clusters in a general way and fully comprehend the evolving needs of local communities. Given data availability, data for 2018 have been used to obtain a picture of the most up-to-date situation (pre-pandemic). This should be updated with recent data to assess the improvement of the connectivity and accessibility of urban systems and assess it over time. The analysis of a longitudinal data panel on clusters' evolution could reveal interesting insights on the existence of pathdependent development processes, which can affect both firms' specialization and the accessibility of urban systems. Despite the visualization of the network showing interesting insights on the regional distribution of economic activities and their connections, the analytical approach presented can be improved by integrating other data and methods to assess the accessibility and connectivity of urban systems. For example, data on travel time and travel costs for the LMAs can provide further information on the accessibility of urban systems. In this direction, analytical methods to analyze the economic environment can be included (i.e., core-periphery models) to catch the regional environment's socio-economic dynamics by highlighting the more specialized urban systems in the region.

Socio-economic data can be improved by introducing additional and purposefully selected indicators. For example, data on social vulnerabilities, COVID-19 impacts, and the provision of public health-related services can lead to a broader picture of the evolution of the demand for public services in urban areas. Indicators can also be complemented by information from the existing best practices on the topic. In the case under investigation, where the integrated planning approach is difficult to be operationalized, such an analytical approach can facilitate the interpretation of urban systems' dynamics and local communities' needs. Finally, In the light of the changing needs of local communities emerging from the pandemic outbreak, such a perspective requires a cooperative dialogue of a wide range of actors pushing for better multi-level governance that embraces urban stakeholders and citizens.

Author Contributions: Conceptualization, C.B.; methodology, C.B., N.H., F.M.; software, N.H. and P.P.; validation, C.B. and P.P.; formal analysis, F.M. and N.H.; investigation, F.M. and N.H.; resources, F.M. and N.H.; data curation, F.M. and N.H. writing-original draft preparation, F.M. and N.H.; writing - review and editing, C.B. and P.P.; visualization, N.H. and P.P.; supervision, C.B.; project administration, C.B.; funding acquisition, C.B. and P.P. All authors have read and agreed to the published version of the manuscript. 
Funding: This research work is the result of the synergetic activity of the TREnD (Transition with Resilience for Evolutionary Development) and ZES (opportunity Zones for innovation EcosystemS governance) Projects, which have received funding from the European Union's Horizon 2020 research and innovation programme under the Marie Skłodowska-Curie grant agreements No. 823952 (TREND) an No. 846144 (ZES), and the SOUND (Smart Open Urban-rural iNnovation Data) Project that has received funding from the Italian Minister of University and Research (MIUR) under the PRIN_Progetti di Ricerca di Rilevante Interesse Nazionale Bando 2017 grant no. 2017JMHK4F.

Institutional Review Board Statement: Not applicable.

Informed Consent Statement: Not applicable.

Data Availability Statement: Publicly available datasets were analyzed in this study. This data can be found here: [http:/ / dati.istat.it/Index.aspx?QueryId=21147].

Conflicts of Interest: The authors declare no conflict of interest. The funders had no role in the design of the study; in the collection, analyses, or interpretation of data; in the writing of the manuscript; or in the decision to publish the results.

\section{References}

1. Eraydin, A. Resilience Thinking for Planning. In Resilience Thinking in Urban Planning, 2nd ed.; Eraydin, A., Taşan-Kok, T.B., Eds.; Springer: Dordrecht, The Netherlands, 2013; pp. 17-38.

2. OECD. Fostering Economic Resilience in a World of Open and Integrated Markets Risks, Vulnerabilities and Areas for Policy Action. Available online: https:/ / www.oecd.org/newsroom/OECD-G7-Report-Fostering-Economic-Resilience-in-a-Worldof-Open-and-Integrated-Markets.pdf (accessed on 24 September 2021).

3. European Commission. European Recovery Plan. Available online: https://ec.europa.eu/info/strategy/recovery-plan-europe_it (accessed on 24 September 2021).

4. Community Based Urban Planning Toolkit (CBUPT) A Step-by-Step Approach to Community Based Urban Planning \& Development in Zimbabwe. Available online: https:/ / www.alnap.org/system/files/content/resource/files/main/51a4a069-8d54-48bdb340-10230a000074.pdf (accessed on 30 November 2021).

5. European Commission. Transition from Institutional to Community-Based Services (Deinstitutionalisation). Available online: https:/ / ec.europa.eu/regional_policy/index.cfm/en/policy/themes/social-inclusion/desinstit (accessed on 14 October 2021).

6. Bylund, J. Joint programming for urban transformations: The making of the JPI Urban Europe Strategic Research and Innovation Agenda. Urban Transform. 2020, 2, 10. [CrossRef]

7. Schalock, R.L.; Brown, I.; Brown, R.; Cummins, R.A.; Felce, D.; Matikka, L.; Keith, K.D.; Parmenter, T. Conceptualization, measurement, and application of quality of life for persons with intellectual disabilities: Report of an international panel of experts. Ment. Retard. 2022, 6, 457-470. [CrossRef]

8. Kozma, A.; Mansell, J.; Beadle-Brown, J. Outcomes in different residential settings for people with intellectual disability: A systematic review. Am. J. Intellect. Dev. Disabil. 2009, 3, 192-222. [CrossRef] [PubMed]

9. Mansell, J.; Beadle-Brown, J. Dispersed or clustered housing for adults with intellectual disability: A systematic review. J. Intellect. Dev. Disabil. 2009, 34, 313-323. [CrossRef]

10. The Ultimate Technical Guide to Urban Footprint. By Calthorpe Analytics. Available online: https://urbanfootprint.com/wpcontent/uploads/2017/11/UrbanFootprint-Technical-Guide-v2-3.pdf (accessed on 12 September 2021).

11. Zhang, F.; Dezhi, L.; Ahrentzen, S.; Zhanga, J. Assessing spatial disparities of accessibility to community-based service resources for Chinese older adults based on travel behavior: A city-wide study of Nanjing, China. Habitat Int. 2019, 88, 101984. [CrossRef]

12. UN Urban Resilience Hub. Available online: https://urbanresiliencehub.org/articles/caring-beyond-city-lines/ (accessed on 10 October 2021).

13. OECD. Can Social Protection Be an Engine for Inclusive Growth; Development Centre Studies, OECD Publishing: Paris, France, 2019. [CrossRef]

14. Hughes, T.; Scott, K.; Maassen, P. Improving Public Services: Guidance for Developing. Available online: https://www opengovpartnership.org/wp-content/uploads/2017/06/OGP_public-service-guidance.pdf (accessed on 20 October 2021).

15. United Nations, Department of Economic and Social Affairs Sustainable Development. Available online: https://sdgs.un.org/ goals (accessed on 28 October 2021).

16. Gibson, D.; Angus, P.; Braddock, D.; Fortune, N.; Johnstone, H.; Madden, R.; Mason, F. Deinstitutionalisation: The Move Toward Community-Based Care. In Australias Welfare 2001: Services and Assistance; Australian Institute of Health and Welfare: Canberra, Australia, 2001; pp. 96-139.

17. Emerson, E.; Hatton, C. Moving Out: The Impact of Relocation from Hospital to Community on the Quality of Life of People with Learning Disabilities; HM Stationery Office: London, UK, 1994.

18. Kim, S.; Larson, S.A.; Lakin, K.C. Behavioural outcomes of deinstitutionalisation for people with intellectual disability: A review of US studies conducted between 1980 and 1999. J. Intellect. Dev. Disabil. 2001, 26, 35-50. [CrossRef] 
19. Mansell, J.; Knapp, M.; Beadle-Brown, J.; Beecham, J. Deinstitutionalisation and Community Living-Outcomes and Costs: Report of a European Study. Volume 2: Main Report; University of Kent: Canterbury, UK, 2007.

20. Mansell, J.; Beadle-Brown, J. Deinstitutionalisation and community living: Position statement of the comparative policy and practice special interest research group of the international association for the scientific study of intellectual disabilities. J. Intellect. Disabil. Res. 2010, 54, 104-112. [CrossRef]

21. Young, L.; Sigafoos, J.; Suttie, J.; Ashman, A.; Grevell, P. Deinstitutionalisation of persons with intellectual disabilities: A review of Australian studies. J. Intellect. Dev. Disabil. 1998, 23, 155-170. [CrossRef]

22. Hatton, C.; Waters, J.; Duffy, S.; Senker, J.; Crosby, N.; Poll, C.; Tyson, A.; O’Brien, J.; Towell, D. A Report on In- Control's Second Phase. In Evaluation and Learning 2005-2007; InControl: London, UK, 2008.

23. Poll, C.; Duffy, S.; Hatton, C.; Sanderson, H.; Routledge, M. A Report on in Control's First Phase, 2003-2005'; InControl Publications: London, UK, 2006.

24. Deakin, M. A Community-Based Approach to Sustainable Urban Regeneration. J. Urban Technol. 2009, 16, 91-112. [CrossRef]

25. Wilson, M.G.; Lavis, J.N.; Guta, A. Community-based organizations in the health sector: A scoping review. Health Res. Policy Syst. 2012, 10, 1-9. [CrossRef]

26. Bruce, A.; Clarson, D. Assessing the potential and limits of community-based initiatives in urban regeneration: Three decades of experience on Sheffield's Manor estate. Reg. Stud. Reg. Sci. 2017, 4, 80-93. [CrossRef]

27. Sharifi, A.; Chelleri, L.; Fox-Lent, C.; Grafakos, S.; Pathak, M.; Olazabal, M.; Moloney, S.; Yumagulova, L.; Yamagata, Y. Conceptualizing Dimensions and Characteristics of Urban Resilience: Insights from a Co-Design Process. Sustainability 2017, 9 , 1032. [CrossRef]

28. Urban Europe, Joint European Solutions, Transition towards Sustainable and Liveable Urban Futures. The Strategic Research and Innovation Agenda of JPI Urban Europe. Available online: https://jpi-urbaneurope.eu/wp-content/uploads/2016/05/JPIUrban-Europe-SRIA-Strategic-Research-and-Innovation-Agenda.pdf (accessed on 15 June 2021).

29. Metropolis. The Metropolitan Scale of Resilience. Available online: https://www.metropolis.org/sites/default/files/issue_ paper_3-the_metropolitan_scale_of_resilience.pdf (accessed on 20 October 2021).

30. Noll, M.; Riegler, J.; Solerod, M.; Gollner, C.; Theierling, S. Driving Urban Transitions. Report on the Agora Strategic Dialogues, Urban Europe. Available online: https://jpi-urbaneurope.eu/wp-content/uploads/2020/10/DUT-AGORA-online-1.pdf (accessed on 22 July 2021).

31. Bifulco, L.; Cementeri, L. Governance and Participation in Local Welfare: The Case of the Italian Piani di Zona. Soc. Policy Adm. 2008, 42, 211-227. [CrossRef]

32. Regione Calabria, Piano Sociale 2020-2022. Available online: https://sis.welfarecalabria.it/resources/Piano\%20Sociale_Regione\% 20Calabria_22.12.2020.pdf (accessed on 13 October 2021).

33. Regione Campania, Politiche Sociali-Ambiti Territoriali. Available online: http://www.sito.regione.campania.it/politichesociali/ ambiti_territoriali/index_ambiti_territoriali.htm (accessed on 15 October 2021).

34. Regione Calabria, La Pianificazione Territoriale, le Linee di Indirizzo e la Connessione con la Programmazione per il Contrasto alla Povertaà e la Promozione Dell'inclusione Sociale. Available online: https://sis.welfarecalabria.it/sac/ recuperadocumentopubblico/525521/0 (accessed on 15 October 2021).

35. Regione Lombardia, Piano dei Servizi, Linee Guida alla Redazione. Available online: https://www.regione.lombardia.it/ wps/wcm/connect/80e446dd-c205-460b-b4e5-9d39df50dafc/Piano+dei+Servizi+-+Linee+guida+alla+redazione.pdf?MOD= AJPERES\&CACHEID=ROOTWORKSPACE-80e446dd-c205-460b-b4e5-9d39df50dafc-mlYcJMn (accessed on 24 October 2021).

36. Porter, M. The economic performance of regions. Reg. Stud. 2003, 37, 549-578. [CrossRef]

37. Frank, B.; Delano, D.; Schaefer-Caniglia, B. Urban systems: A socio-ecological system perspective. Sociol. Int. J. 2017, 1, 1-8. [CrossRef]

38. Searle, G.; Sigler, T.J.; Martinus, K. Firm evolution and cluster specialization: A social network analysis of resource industry change in two Australian cities. Reg. Stud. Reg. Sci. 2018, 5, 369-387. [CrossRef]

39. Sigler, T.J. After the 'world city'has globalised: Four agendas towards a more nuanced framework for global urban research. Geogr. Compass 2016, 10, 389-398. [CrossRef]

40. Huggins, R.; Prokop, D. Network structure and regional innovation: A study of university-industry ties. Urban Stud. 2017, 54, 931-952. [CrossRef]

41. Cassi, L.; Morisson, A.; Ter Wal, A.L. The evolution of trade and scientific collaboration networks in the global wine sector: A longitudinal study using network analysis. J. Econ. Geogr. 2007, 7, 311-334. [CrossRef]

42. Glückler, J. Economic geography and the evolution of networks. J. Econ. Geogr. 2007, 7, 619-634. [CrossRef]

43. Grabher, G. Trading routes, bypasses, and risky intersections: Mapping the travels of networks' between economic sociology and economic geography. Prog. Hum. Geogr. 2006, 30, 163-189. [CrossRef]

44. Istat, Indagini sul Reddito e Condizioni di Vita. Available online: https://www.istat.it/it/files//2020/05/18_Calabria_Scheda. pdf (accessed on 18 October 2021).

45. Eurostat, Gross Domestic Product (GDP) at Current Market Prices by NUTS 2 Region. Available online: https:/ / ec.europa.eu/ eurostat/web/main/data/database (accessed on 14 October 2021).

46. Folta, T.B.; Cooper, A.C.; Baik, Y. Geographic cluster size and firm performance. J. Bus. Ventur. 2006, 21, 217-242. [CrossRef] 
47. Sölvell, Ö.; Ketels, C.; Lindqvist, G. Industrial specialization and regional clusters in the ten new EU member states. Compet. Rev. Int. Bus. J. 2008, 18, 104-130. [CrossRef]

48. Istat, Labour Market Area: Eu-Ttwa Method: Improvements, Documentation and Sharing Knowledge Activities. Available online: https:/ / www.istat.it/en/archive/182743 (accessed on 20 October 2021).

49. Naumanen, M. European Panorama of Clusters And industrial Change: Emerging Industries: Driving Strength in 10 Cross-Sectoral Industries; European Commission EC: Publication Office of the European Union: Luxembourg, 2019.

50. Istat, Classificazione Delle Attività Economiche ATECO 2007. Available online: https://www.istat.it/it/archivio/1788https: //www.istat.it/it/archivio/17888 (accessed on 17 October 2021).

51. Crosseley, N. The Social World of the Network. Combining Qualitative and Quantitative Elements in Social Network Analysis 2010. Sociologica 2010, 1, 1-34. [CrossRef]

52. Costa, L.F.; Rodrigues, F.A.; Cristino, A.S. Complex networks: The key to systems biology. Genet. Mol. Biol. 2008, 31, 591-601. [CrossRef]

53. Fletcher, R.; Barrett, N. Embeddedness and the evolution of global networks: An Australian case study. Ind. Mark. Manag. 2001, 30, 561-573. [CrossRef]

54. Glueckler, J.; Doreian, P. Social network analysis and economic geography-positional, evolutionary and multi-level approaches. J. Econ. Geogr. 2016, 16, 1123-1134.

55. OECD. OECD Policy Responses to Coronavirus (COVID-19) Cities Policy Responses. 2020. Available online: https:/ www.oecd. org/coronavirus/policy-responses/cities-policy-responses-fd1053ff/\#section-d1e406 (accessed on 11 January 2022).

56. Batty, M. Planning the 21st Century City-Four Snapshots for a New Science. Int. Rev. Spat. Plan. Sustain. Dev. 2021, 9, 1-9. [CrossRef] 